\title{
Psychological Correlates to Dysfunctional Eating Patterns among Morbidly Obese Patients Accepted for Bariatric Surgery
}

\author{
Hege Gade ${ }^{a, b} \quad$ Jan Harald Rosenvinge ${ }^{b} \quad$ Jøran Hjelmesæth ${ }^{a, c}$ \\ Oddgeir Friborg ${ }^{b}$ \\ ${ }^{a}$ Morbid Obesity Centre, Vestfold Hospital Trust, Tønsberg, ${ }^{b}$ Department of Psychology, \\ University of Tromsø, Tromsø, ' ${ }^{\circ}$ Department of Endocrinology, Morbid Obesity and \\ Preventive Medicine, Institute of Clinical Medicine, University of Oslo, Oslo, Norway
}

Key Words

Obesity - Dysfunctional eating behaviours - Personality traits · Affective symptoms - Bariatric surgery

\begin{abstract}
Objective: To examine the relationships between dysfunctional eating patterns, personality, anxiety and depression in morbidly obese patients accepted for bariatric surgery. Design: The study used cross-sectional data collected by running a randomized controlled trial (http:// clinicaltrials.gov/ct2/show/NCT01403558). Subjects: A total of 102 patients (69 women, 33 men) with a mean (SD) age of 42.6 (9.8) years and a mean BMI of $43.5(4.4) \mathrm{kg} / \mathrm{m}^{2}$ participated. Measurements: Measurements included the NEO-PI-R (personality: neuroticism, extroversion, openness, conscientiousness and agreeableness), the TFEQ-R-21 (dysfunctional eating: emotional eating (EE), uncontrolled eating (UE) and cognitive restraint of eating (CR)) and the HADS (anxiety and depression). Results: The personality traits neuroticism and conscientiousness were more strongly correlated with dysfunctional eating than anxiety and depression. These differences were most pronounced for emotional and cognitive restraint of eating. Emotional eating occurred more often in female than in male patients, a finding that was partially mediated by neuroticism but not by anxiety and depression. Conclusion: Personality traits may be important to address in the clinical management of morbidly obese patients seeking bariatric surgery as neuroticism is particularly salient in female patients displaying an emotional eating behaviour.


Gade et al.: Psychological Correlates to Dysfunctional Eating Patterns among Morbidly Obese Patients Accepted for Bariatric Surgery

\section{Introduction}

Approximately $10-25 \%$ of obese patients considered for or treated by bariatric surgery have dysfunctional eating patterns [1-4]. Dysfunctional eating patterns can be operationalized as emotional eating (EE), uncontrolled eating (UE) and cognitive restraint of eating (CR) [5]. EE serves to regulate negative mood states like feeling lonely, anxious or depressed. On the other hand, people with UE tend to lose control over their eating behaviour when feeling hungry while people with CR tend to overly restrict their food intake in order to control weight, body shape or body composition. Hence, all three patterns serve to regulate or suppress negative emotional states. These patterns may result in overconsumption of energy-dense food [6], and extreme variations may qualify for a DSM-IV-defined unspecified eating disorder or a binge eating disorder (BED) [7].

The clinical importance of pre-surgical BED symptoms for the outcome of bariatric surgery is unsettled. One study [8] reported a development of grazing eating behaviours, but with less amount of food. Other studies reported no predictive value [9], notably with respect to weight loss [10], but rather that suboptimal weight loss was predicted by the level of postoperative BED symptoms.

Measures of dysfunctional eating seem to show a more consistent picture [3, 11-14] for predicting weight regain and impaired post-operative weight loss.

Depression and anxiety are common comorbid conditions in patients seeking bariatric surgery $[15,16]$ - with a prevalence of $16 \%$ and $22 \%$, respectively [17]. Depression is known to disrupt self-regulatory sleep and eating behaviours [18] related to impaired motivation and anhedonia. Anxiety on the other hand may prompt worries about future consequences of non-sustainable changes and a reluctance to implement behavioural changes. Also, mood disorders appear to be a consequence of being morbidly obese [19].

A psychological construct of large impact is personality as it permeates most aspects of humans' cognitive and emotional life and behaviour [20], including eating behaviours. Dysfunctional eating patterns observed among morbidly obese patients seem to be related to personality traits [2, 21-23] and, in particular, to neurotic personality traits [24-26]. However, the exact nature of this relationship in conjunction with gender and symptoms of mood disorders is not known. Though, in female pre-bariatric obese patients, two broad personality subtypes have been observed [27]: one normal and a second psychopathological type. Patients of the latter type score higher on 'neuroticism', and lower on the traits 'extraversion', 'agreeableness' and 'conscientiousness'. They also display significantly more binge eating and dysfunctional eating behaviours that may have emotion-regulating functions.

Women constitute the majority of morbidly obese persons including those seeking bariatric surgery [28]. Disturbed eating patterns are also more prevalent among women in the general population [29], and EE seems to be more frequent among morbidly obese women [30]. The gender differences in the correlation between eating behaviours and personality traits have been reported as small to negligible in the obesity literature [24]. The findings have also been inconsistent due to a small number of participating patients and failures to include bariatric surgery patients. In the current study we therefore aimed to explore genderrelated differences in dysfunctional eating behaviours in patients admitted for bariatric surgery and the mediating role of specific personality traits as well as of symptoms of depression and anxiety.

We hypothesized that 1 ) female morbidly obese patients accepted for bariatric surgery had a higher level of emotional eating than men, and 2) that personality traits, anxiety and depression may partly explain hypothesis 1 indirectly via mediation. 
Gade et al.: Psychological Correlates to Dysfunctional Eating Patterns among Morbidly Obese Patients Accepted for Bariatric Surgery

\section{Material and Methods}

\section{Participants}

The inclusion criteria were obesity grade 2 (BMI 35.0-39.9 kg/m²) and at least one obesity-related comorbidity or obesity grade $3\left(\mathrm{BMI} \geq 40.0 \mathrm{~kg} / \mathrm{m}^{2}\right.$ ) and being accepted for bariatric surgery at the Morbid Obesity Centre at Vestfold Hospital Trust. There were no exclusion criteria.

We included 102 patients ( 69 females and 33 males) consecutively admitted between September 2011 and June 2012 for bariatric surgery at the Morbid Obesity Centre at Vestfold Hospital Trust in Norway. The mean BMI was 43.5 (SD 4.9) $\mathrm{kg} / \mathrm{m}^{2}$, and the majority $(79.4 \% \mathrm{n}=81$ ) had obesity grade 3 .

\section{Measures}

Descriptive variables comprised age, gender, educational level as well as body weight and body height.

The Norwegian version of the Three Factor Eating Questionnaire (TFEQ-R-21) validated for measuring eating behaviours in obese individuals $[5,31]$ was used to measure dysfunctional eating patterns. It consists of 21 items comprising the subscales 'emotional eating' (EE; 6 items), 'uncontrolled eating' (UE; 9 items) and 'cognitive restraint of eating' (CR; 6 items). The domain scores range from 0 to 100. The level of dysfunction is indicated by higher scores on all subscales. All subscales have shown high internal consistency (Cronbach's $\alpha$ ranging from 0.70 to 0.90 ) [31].

The Norwegian version of the NEO Personality Inventory-Revised (NEO-PI-R) [32] was used to assess personality traits. The NEO-PI-R is used world-wide and is based on the Five Factor Model (FFM) of personality [33]. It consists of 240 items using a five-point Likert scale to measure five domains of personality: neuroticism $(\mathrm{N})$, extraversion (E), openness (O), agreeableness (A) and conscientiousness (C). The domain scores are each composed of six facet scores, and hence, mean raw scores were created for the five domain scores and the 30 facet scores and used in the correlation/regression analyses. Higher scores indicated more of the trait. Genderadjusted standardized T-scores $(M=50, S D=10)$ were additionally used for descriptive purposes.

Anxiety and depression were measured by the Hospital Anxiety and Depression Scale (HADS) [34]. HADS is a self-report measure of non-vegetative affective symptoms [34, 35] where seven items assess depression (HADS-D) and seven items measure anxiety (HADS-A). Items are scored 0-3 yielding a range of $0-21$ within each subscale. In Norway a cut-off $\geq 8$ is used to indicate a probable diagnosis of depression or anxiety [36]. The Cronbach's $\alpha$ for HADS-A vary from 0.68 to 0.93 (mean 0.83), and for HADS-D from 0.67 to 0.90 (mean 0.82) $[34,36]$.

\section{Procedures}

Four months prior to bariatric surgery and after the completion of the informed consent form, data were collected by a web-based solution (Metreno and FluidSurveys) during the hospital visit.

Height, using a wall-mounted stadiometer, and weight were measured to calculate the BMI $\left(\mathrm{kg} / \mathrm{m}^{2}\right)$.

The procedures were initiated after the study had been approved by the Regional Committee for Medical and Health Research Ethics (2010/2071a).

\section{Statistical Analyses}

The SPSS version 17 was used for all statistical analyses. Group differences were examined with independent sample t-tests (continuous data) and Fisher's exact tests (categorical data). Associations between the continuous variables were examined with Pearson's bivariate correlations and hierarchical multiple stepwise regression analyses. A hierarchical approach was used to assess how much of the variation in dysfunctional eating patterns was related to three blocks of variables: 1) demographic information (i.e., age, gender, educational level and BMI), 2) affective symptoms (i.e., anxious and depressed mood) and 3) personality traits (i.e., NEO-PI-R).

Given the number of analyses, the $\alpha$ levels were set to 0.001 in the bivariate analyses (tables 1,2$)$ and 0.01 in the multivariate analysis (table 3 ), and, accordingly, p values $\leq 0.001$ and $\leq 0.01$ were considered significant.

\section{Multiple Mediation Analysis}

A multiple mediation analysis was conducted using an SPSS macro by Preacher and Hayes [37] allowing covariate control. The contributions by multiple mediators, i.e. personality, anxiety and depression, were simultaneously examined as indirect paths. Bootstrapped standard errors were estimated through 1,000 re-samplings [37] to obtain correct confidence intervals for the indirect path or the mediator coefficient. 
Gade et al.: Psychological Correlates to Dysfunctional Eating Patterns among Morbidly Obese Patients Accepted for Bariatric Surgery

Table 1. Descriptive total sample and gender specific statistics for BMI, age, eating behaviours, anxiety, depression and personality for patients accepted for bariatric surgery $(\mathrm{N}=102)$

\begin{tabular}{|c|c|c|c|c|c|}
\hline & $\begin{array}{l}\text { Men }(n=33), \\
M(S D)\end{array}$ & $\begin{array}{l}\text { Women }(n=69) \text {, } \\
\text { M (SD) }\end{array}$ & $\mathrm{t}$ & g & $\alpha$ \\
\hline$B M I$ & $43.3(5.7)$ & $43.6(4.4)$ & 0.29 & 0.06 & \\
\hline Age & $45.6(10.3)$ & $41.2(9.3)$ & 2.17 & -0.46 & \\
\hline \multicolumn{6}{|l|}{ Eating behaviors } \\
\hline Emotional eating & $35.0(20.9)$ & $60.7(24.1)$ & $5.26^{*}$ & 1.11 & 0.92 \\
\hline Uncontrolled eating & $46.4(19.2)$ & $50.2(18.7)$ & 0.96 & 0.20 & 0.73 \\
\hline Cognitive restraint & $42.8(19.3)$ & $44.8(21.1)$ & 0.46 & 0.10 & 0.84 \\
\hline Anxiety & $4.9(3.5)$ & $7.6(3.9)$ & $3.40^{*}$ & 0.72 & 0.84 \\
\hline Depression & $4.9(3.5)$ & $5.2(3.4)$ & 0.47 & 0.10 & 0.78 \\
\hline \multicolumn{6}{|l|}{ Personality traits } \\
\hline \multicolumn{6}{|l|}{ Unadjusted raw scores } \\
\hline Neuroticism & $82.0(26.7)$ & $103.3(25.4)$ & $3.89^{*}$ & 0.97 & 0.89 \\
\hline Extraversion & $103.4(23.8)$ & 109.9 (19.8) & 1.46 & 0.31 & 0.78 \\
\hline Openness & $108.5(15.5)$ & $104.4(17.7)$ & 1.16 & -0.24 & 0.65 \\
\hline Agreeableness & $129.4(16.1)$ & $122.6(20.2)$ & 1.82 & -0.36 & 0.75 \\
\hline Conscientiousness & $115.0(22.6)$ & $111.8(19.5)$ & -0.74 & -0.16 & 0.84 \\
\hline \multicolumn{6}{|l|}{ Adjusted T scores } \\
\hline Neuroticism & $52.8(11.1)$ & $54.9(11.1)$ & 0.77 & 0.18 & \\
\hline Extraversion & $42.2(11.2)$ & $45.8(9.8)$ & 0.27 & 0.35 & \\
\hline Openness & $44.6(8.0)$ & $43.0(9.6)$ & 0.19 & -0.17 & \\
\hline Agreeableness & $52.7(12.5)$ & $53.3(10.6)$ & 0.13 & 0.06 & \\
\hline Conscientiousness & $48.9(11.0)$ & $49.5(10.3)$ & 0.72 & 0.05 & \\
\hline
\end{tabular}

$\mathrm{t}=$ Student's t-test; ${ }^{*} \mathrm{p}<0.001 ; \mathrm{g}=$ Hedge's g effect size; $\alpha=$ Cronbach's $\alpha$.

\section{Results}

The 102 participants (69 women, 33 men) had a mean (SD) age of 42.6 (9.8) years and a BMI of $43.5(4.9) \mathrm{kg} / \mathrm{m}^{2}$. Women reported significantly more emotional eating and anxiety symptoms. The unadjusted personality scores showed higher neuroticism in women, but no gender differences were found in the norm-adjusted T-scores (table 1).

\section{Anxiety and Depression}

Using the HADS cut-off score $\geq 8$ for a possible diagnosis, no gender differences were found for the prevalence of anxiety (men 33\%, women $45 \%, \mathrm{p}=0.29$ ) or depression (men $24 \%$, women $24 \%$, $\mathrm{p}=0.999$ ).

\section{Bivariate Associations between Personality Traits, Eating Behaviours and Mood}

The personality trait neuroticism was strongly positively correlated with EE, UE, anxiety and depression, and negatively with CR and age. Conscientiousness was negatively correlated with EE, UE, depression and anxiety, and positively correlated with CR.

Regression Analyses Predicting Emotional Eating, Uncontrolled Eating and Cognitive Restraint

The hierarchical regression models (table 3 ) showed in the first step that women reported significantly more EE than men, while high BMI was related to higher levels of dysfunction on all three eating pattern measures. In the second step, patients with more anxiety and, but to a lesser extent, more depression reported more EE relative to those with less anxiety or depression. Depressive symptoms were positively related with a dysfunctional eating pattern 
Gade et al.: Psychological Correlates to Dysfunctional Eating Patterns among Morbidly

Obese Patients Accepted for Bariatric Surgery

Table 2. Correlation coefficients between the demographic variables, eating behaviours, anxiety, depression and personality traits $(\mathrm{N}=102)^{*}$

\begin{tabular}{|c|c|c|c|c|c|c|c|c|c|c|c|c|}
\hline & 1 & 2 & 3 & 4 & 5 & 6 & 7 & 8 & 9 & 10 & 11 & 12 \\
\hline \multicolumn{13}{|l|}{1 Emotional eating } \\
\hline 2 Uncontrolled eating & 0.61 & & & & & & & & & & & \\
\hline 3 Cognitive restraint & -0.36 & -0.42 & & & & & & & & & & \\
\hline 4 Anxiety & 0.52 & 0.32 & -0.19 & & & & & & & & & \\
\hline 5 Depression & 0.38 & 0.45 & -0.28 & 0.44 & & & & & & & & \\
\hline 6 Age & -0.09 & 0.11 & 0.12 & -0.26 & 0.03 & & & & & & & \\
\hline $7 \mathrm{BMI}$ & 0.27 & 0.20 & -0.22 & 0.05 & 0.19 & -0.04 & & & & & & \\
\hline 8 Neuroticism & 0.63 & 0.44 & -0.37 & 0.70 & 0.49 & -0.31 & 0.21 & & & & & \\
\hline 9 Extraversion & -0.12 & -0.21 & 0.17 & -0.11 & -0.42 & -0.08 & -0.07 & -0.32 & & & & \\
\hline 10 Openness & -0.08 & -0.06 & 0.04 & -0.04 & -0.08 & 0.06 & 0.01 & -0.13 & 0.43 & & & \\
\hline 11 Agreeableness & -0.00 & -0.18 & 0.28 & -0.01 & -0.16 & 0.21 & -0.04 & -0.18 & 0.03 & 0.14 & & \\
\hline 12 Conscientiousness & -0.43 & -0.43 & 0.42 & -0.27 & -0.35 & 0.16 & -0.24 & -0.56 & 0.32 & 0.23 & 0.32 & \\
\hline
\end{tabular}

*Pearson correlations above 0.31 are significant at $\mathrm{p}<0.001$.

Table 3. Hierarchical stepwise multiple regression analyses predicting dysfunctional eating behaviours

\begin{tabular}{|c|c|c|c|c|c|c|c|c|c|}
\hline \multirow[t]{2}{*}{ Step / variable } & \multicolumn{3}{|c|}{ Emotional eating } & \multicolumn{3}{|c|}{ Uncontrolled eating } & \multicolumn{3}{|c|}{ Cognitive restraint } \\
\hline & initial $\beta$ & final $\beta$ & $\operatorname{adj} R^{2}$ & initial $\beta$ & final $\beta$ & $\operatorname{adj} R^{2}$ & initial $\beta$ & final $\beta$ & $\operatorname{adj} R^{2}$ \\
\hline \multicolumn{10}{|l|}{ Step 1} \\
\hline Gender & $-0.47^{* * *}$ & $-0.29 * * *$ & & & & & & & \\
\hline BMI & $0.26^{* *}$ & 0.16 & 0.27 & 0.20 & 0.07 & 0.03 & -0.22 & -0.11 & 0.04 \\
\hline \multicolumn{10}{|l|}{ Step 2} \\
\hline Anxiety & $0.40^{* * *}$ & 0.12 & & & & & & & \\
\hline Depression & 0.18 & 0.11 & 0.43 & $0.43^{* * *}$ & $0.33^{* * *}$ & 0.20 & -0.24 & -0.13 & 0.09 \\
\hline \multicolumn{10}{|l|}{ Step 3} \\
\hline Neuroticism & & $0.36^{* *}$ & 0.48 & & & & & & \\
\hline Conscientiousness & & & & & $-0.30^{* *}$ & 0.27 & & $0.34^{* * *}$ & 0.18 \\
\hline
\end{tabular}

across all three measures (i.e., EE, UE and CR), having the largest negative impact on UE. Adding of personality traits in the last step showed that neuroticism was positively associated with EE, but importantly, this personality trait also rendered anxiety and depression nonsignificant. For the other two outcomes, conscientiousness was the most significant personality trait, also substituting the relation depression had with CR. In both cases conscientiousness represented a protective effect. The fact that no outliers and non-linear regression effects were detected argues for the generalizability of the regression models.

Due to the statistically significant domain scores for neuroticism and conscientiousness, follow-up regression analyses were conducted by replacing these domain scores with their facet scores. For EE, impulsiveness $(\beta=0.28, p=0.001)$ and depression $(\beta=0.29, p=0.006)$ 
Gade et al.: Psychological Correlates to Dysfunctional Eating Patterns among Morbidly Obese Patients Accepted for Bariatric Surgery

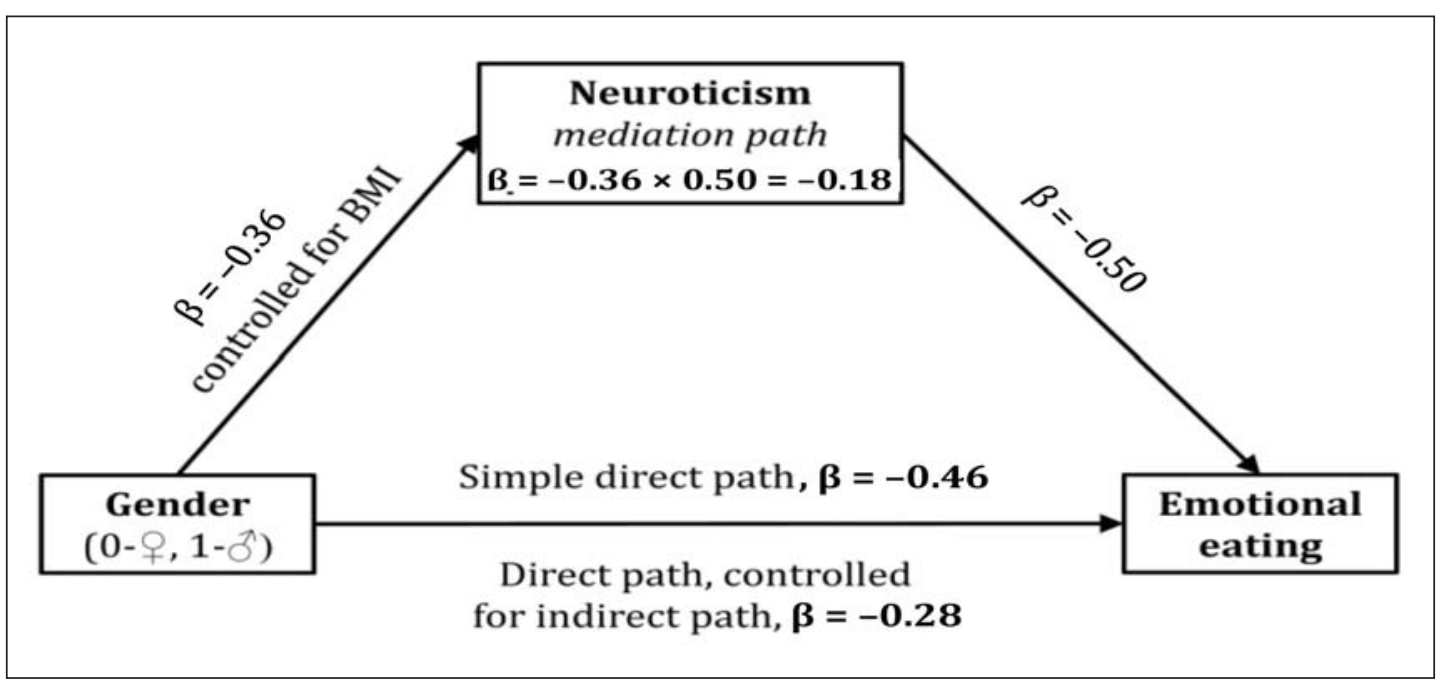

Fig. 1. The mediation model with standardized beta coefficients.

were the most important neuroticism facets in explaining EE (total $\mathrm{R}^{2}=0.56$ ). For UE, the neuroticism facets impulsiveness $(\beta=0.26, p=0.005)$ and vulnerability $(\beta=0.27, p=0.007)$ contributed most to the regression model (total $\mathrm{R}^{2}=0.35$ ). For $\mathrm{CR}$, the conscientiousness and neuroticism facets dutifulness $(\beta=0.34, p=0.001)$ and impulsiveness $(\beta=-0.34, p=0.001)$, respectively, contributed most to the model (total $R^{2}=0.33$ ). Using facet rather than domain scores increased the amount of variance explained $\left(\mathrm{R}^{2}\right)$ considerably, and in particular for $\mathrm{CR}$.

\section{Mediation Analysis of the Gender Differences in EE}

A multiple mediation analysis was conducted to examine if personality, depression or anxiety played a role as mediators for the relationship between gender and EE. Personality was the only significant mediator. The initial direct path (gender-EE, controlled for BMI) was $\beta=-0.46(p<0.001)$, but dropped to $\beta=-0.28(p<0.001)$ after adding personality as the indirect path $\beta=-0.18(95 \% \mathrm{CI}-0.29$ to -0.09$)$. The indirect path explained $39 \%(0.18 / 0.46)$ of the total variance in EE (fig. 1).

Taken together, the findings indicated a stronger impact of personality on dysfunctional eating compared with anxiety and depression.

\section{Discussion}

We hypothesized that female morbidly obese patients accepted for bariatric surgery had a higher level of emotional eating than men and, secondly, that personality traits, anxiety and depression partly explained the variation in eating behaviours.

Our major finding was that personality traits were more firmly related to dysfunctional eating patterns than mood disorder symptoms. Anxiety and depression were weakly related to such patterns when personality traits were controlled for. Neuroticism and conscientiousness were the prime personality traits involved in EE and UE/CR and could be ascribed a vulnerable and protective role, respectively. Moreover, EE occurred more often in female patients as previously reported $[24,25,30]$. We also found that neuroticism partially mediated this relationship, thus indicating a putative mechanism. 
Gade et al.: Psychological Correlates to Dysfunctional Eating Patterns among Morbidly Obese Patients Accepted for Bariatric Surgery

\section{The Role of Personality in Gender Differences in Emotional Eating}

As reported by others [38, 39], women displayed more neuroticism and emotional eating. However, our results extended these findings by indicating that the gender-related differences in EE were partially explained by neuroticism (explaining almost half of the total variance), but neither by anxiety nor depression. The mediating role of neuroticism may indicate that this trait is a key factor to modify dysfunctional eating patterns of female bariatric surgery patients. This stands in contrast to Elfhag and Morey [24] who found negligible gender differences in the correlations between dysfunctional eating patterns and personality traits, such as neuroticism. We suspect that the contradictive results may be due to the use of standardized T-scores adjusting for gender differences in the study of Elfhag and Morey [24], whereas our analyses are based on unadjusted raw scores which do not mask naturally occurring gender-specific personality differences. The generally larger effect sizes for the gender differences in the unadjusted raw scores compared with the adjusted standardized T-scores make this interpretation plausible.

\section{Symptoms, Personality and Emotional Eating}

Our findings concur with previous studies $[1,24,25]$ supporting the role of personality traits in disordered eating patterns. As personality traits are quite stable over time [19], eating behaviours are persistently influenced by these traits in contrast to the fluctuating influence of more time-limited psychological conditions like mood disorders. Hence, personality traits, like neuroticism, may be clinically important to address in addition to mood disorders as such traits are part of the psychological makeup of an individual that always exert a potential negative effect. A neurotic person is continuously exposed to emotional turmoil elicited by the liability to react to negative life events. Improved self-regulation of inherent neurotic traits may facilitate the achievement of weight maintenance goals by reducing the tendency to use dysregulated and dysfunctional eating patterns to cope with stress and daily hassles that may otherwise elicit anxiety or depression.

Notably, the neuroticism facet 'impulsiveness' contributed to explain a variation in all kinds of dysfunctional eating patterns. This finding concurs with a recent review article [40], which indicates that obese patients with or without BED display dysregulated eating behaviours due to the tendency of more spontaneous and 'impulse-driven' food intake. One possible implication of these findings is that this personality facet might be a 'key factor' in many different types of dysfunctional eating patterns. This personality trait may thus act as a vulnerability factor in an obesogenic society with a high exposure to energy-dense food and beverages, increasing the liability to develop dysfunctional eating patterns.

The personality trait conscientiousness is manifested by characteristic behaviours such as being organized and having a mental focus on order, control and systematics. High-scoring individuals may therefore stand out as rigid and inefficient if they lack the ability to flexibly adjust their behaviour according to changing situational demands. In the present study, though, the highly conscientious bariatric surgery patients seemed more able to take control over eating. In this respect, conscientiousness may protect against UE and CR and dispose for a higher ability to resist weight gain.

\section{Strengths and Limitations}

Strengths of the present study include the use of a web-based data collection method in a structured hospital setting. This may have reduced loss of variance and the need for imputation due to scattered missing data. Important limitations were the failure to include a diagnostic or self-report measure of BED as well as the cross-sectional design. The latter precludes any causal interpretations and tempers the conclusion that neuroticism may be an intermediate link between gender and emotional eating. Longitudinal data from this research project 
Gade et al.: Psychological Correlates to Dysfunctional Eating Patterns among Morbidly Obese Patients Accepted for Bariatric Surgery

are underway that may more validly examine the direct and indirect causal role of personality factors, anxiety and depression for patients' ability to maintain an adequate post-surgery target weight.

\section{Conclusions}

The present study confirms previous findings [24-27]. Despite being limited by the cross-sectional design, it provides provisional new insights into how personality traits and gender may account for individual differences in emotional eating behaviour among patients admitted for bariatric surgery. Secondly, the study highlights that the interplay between gender, psychological health (i.e., anxiety and depression) and personality constructs (i.e., neuroticism and conscientiousness) are clinically relevant topics for future research.

\section{Disclosure Statement}

No conflicts of interest reported.

\section{References}

1 Stunkard AJ: Eating disorders and obesity. Psychiatr Clin North Am 2011;34:765-771.

$\longrightarrow 2$ Abiles V, Rodriguez-Ruiz S, Abiles J, Mellado C, Garcia A, Perez de la Cruz A, Fernandez-Santaella MC: Psychological characteristics of morbidly obese candidates for bariatric surgery. Obes Surg 2010;20:161-167.

-3 Zimmerman M, Francione-Witt C, Chelminski I, Young D, Boerescu D, Attiullah N, Pohl D, Roye GD, Harrington DT: Presurgical psychiatric evaluations of candidates for bariatric surgery, part 1: reliability and reasons for and frequency of exclusion. J Clin Psychiatry 2007;68:1557-1562.

-4 Pull CB: Current psychological assessment practices in obesity surgery programs: What to assess and why. Curr Opin Psychiatry 2010;23:30-36.

-5 Cappelleri JC, Bushmakin AG, Gerber RA, Leidy NK, Sexton CC, Lowe MR, Karlsson J: Psychometric analysis of the Three-Factor Eating Questionnaire-R21: results from a large diverse sample of obese and non-obese participants. Int J Obes (Lond) 2009;33:611-620.

-6 Foster MT, Warne JP, Ginsberg AB, Horneman HF, Pecoraro NC, Akana SF, Dallman MF: Palatable foods, stress, and energy stores sculpt corticotropin-releasing factor, adrenocorticotropin, and corticosterone concentrations after restraint. Endocrinology 2009;150:2325-2333.

7 American Psychiatric Association: Task Force on DSM-IV: Diagnostic and statistical manual of mental disorders?: DSM-IV-TR, ed 4th. Washington, DC, American Psychiatric Association, 2000.

8 Saunders R: 'Grazing': a high-risk behavior. Obes Surg 2004;14:98-102.

$\checkmark 9$ White MA, Kalarchian MA, Masheb RM, Marcus MD, Grilo CM: Loss of control over eating predicts outcomes in bariatric surgery patients: a prospective, 24-month follow-up study. J Clin Psychiatry 2010;71:175-184.

10 Livhits M, Mercado C, Yermilov I, Parikh JA, Dutson E, Mehran A, Ko CY, Gibbons MM: Preoperative predictors of weight loss following bariatric surgery: systematic review. Obes Surg 2012;22:70-89.

11 Colles SL, Dixon JB, O’Brien PE: Grazing and loss of control related to eating: two high-risk factors following bariatric surgery. Obesity (Silver Spring) 2008;16:615-622.

12 Fischer S, Chen E, Katterman S, Roerhig M, Bochierri-Ricciardi L, Munoz D, Dymek-Valentine M, Alverdy J, le Grange D: Emotional eating in a morbidly obese bariatric surgery-seeking population. Obes Surg 2007;17: 778-784.

13 Dziurowicz-Kozlowska AH, Wierzbicki Z, Lisik W, Wasiak D, Kosieradzki M: The objective of psychological evaluation in the process of qualifying candidates for bariatric surgery. Obes Surg 2006;16:196-202.

14 Grothe KB, Dubbert PM, O'Jile J R: Psychological assessment and management of the weight loss surgery patient. Am J Med Sci 2006;331:201-206.

15 Sarwer DB, Cohn NI, Gibbons LM, Magee L, Crerand CE, Raper SE, Rosato EF, Williams NN, Wadden TA: Psychiatric diagnoses and psychiatric treatment among bariatric surgery candidates. Obes Surg 2004;14:11481156.

16 Lin HY, Huang CK, Tai CM, Lin HY, Kao YH, Tsai CC, Hsuan CF, Lee SL, Chi SC, Yen YC: Psychiatric disorders of patients seeking obesity treatment. BMC Psychiatry 2013;13:1.

17 Kalarchian MA, Marcus MD, Levine MD, Courcoulas AP, Pilkonis PA, Ringham RM, Soulakova JN, Weissfeld LA, Rofey DL: Psychiatric disorders among bariatric surgery candidates: relationship to obesity and functional health status. Am J Psychiatry 2007;164:328-334; quiz 374. 
Gade et al.: Psychological Correlates to Dysfunctional Eating Patterns among Morbidly Obese Patients Accepted for Bariatric Surgery

18 Sullivan PF, Neale MC, Kendler KS: Genetic epidemiology of major depression: review and meta-analysis. Am J Psychiatry 2000;157:1552-1562.

19 Roberts BW, DelVecchio WF: The rank-order consistency of personality traits from childhood to old age: a quantitative review of longitudinal studies. Psychol Bull 2000;126:3-25.

-20 McCrae RR, Costa PT: Personality trait structure as a human universal. Am Psychol 1997;52:509-516.

21 van Hout G, van Heck G: Bariatric psychology, psychological aspects of weight loss surgery. Obes Facts 2009; 2:10-15.

22 van Hout GC, Verschure SK, van Heck GL: Psychosocial predictors of success following bariatric surgery. Obes Surg 2005;15:552-560.

23 Mitchell JE, Selzer F, Kalarchian MA, Devlin MJ, Strain GW, Elder KA, Marcus MD, Wonderlich S, Christian NJ, Yanovski SZ: Psychopathology before surgery in the longitudinal assessment of bariatric surgery-3 (LABS-3) psychosocial study. Surg Obes Relat Dis 2012;8:533-541.

24 Elfhag K, Morey LC: Personality traits and eating behavior in the obese: poor self-control in emotional and external eating but personality assets in restrained eating. Eat Behav 2008;9:285-293.

25 Heaven PC, Mulligan K, Merrilees R, Woods T, Fairooz Y: Neuroticism and conscientiousness as predictors of emotional, external, and restrained eating behaviors. Int J Eat Disord 2001;30:161-166.

26 Provencher V, Begin C, Gagnon-Girouard MP, Tremblay A, Boivin S, Lemieux S: Personality traits in overweight and obese women: associations with BMI and eating behaviors. Eat Behav 2008;9:294-302.

27 Claes L, Vandereycken W, Vandeputte A, Braet C: Personality subtypes in female pre-bariatric obese patients: do they differ in eating disorder symptoms, psychological complaints and coping behaviour? Eur Eat Disord Rev 2013;21:72-77.

28 Buchwald H, Avidor Y, Braunwald E, Jensen MD, Pories W, Fahrbach K, Schoelles K: Bariatric surgery: a systematic review and meta-analysis. JAMA 2004;292:1724-1737.

29 Gotestam KG, Eriksen L, Hagen H: An epidemiological study of eating disorders in Norwegian psychiatric institutions. Int J Eat Disord 1995;18:263-268.

-30 Chesler BE: Emotional eating: a virtually untreated risk factor for outcome following bariatric surgery. ScientificWorldJournal 2012:1-6.

-31 Karlsson J, Persson LO, Sjostrom L, Sullivan M: Psychometric properties and factor structure of the ThreeFactor Eating Questionnaire (TFEQ) in obese men and women. Results from the Swedish Obese Subjects (SOS) study. Int J Obes Relat Metab Disord 2000;24:1715-1725.

32 Martinsen ØL, Østbø LE, Nordvik H: Norske versjoner av NEO PI-R og NEO FFI (Norwegian versions of the NEO PI-R and NEO FFI). J Norw Psychol Assoc 2005;42:421-423.

33 Costa PT, McCrae RR: Domains and facets: Hierarchical personality assessment using the revised NEO personality inventory. J Pers Assess 1995;64:21-50.

34 Bjelland I, Dahl AA, Haug TT, Neckelmann D: The validity of the Hospital Anxiety and Depression Scale. An updated literature review. J Psychosom Res 2002;52:69-77.

-35 Herrmann C: International experiences with the Hospital Anxiety and Depression Scale - a review of validation data and clinical results. J Psychosom Res 1997;42:17-41.

-36 Oyane NM, Bjelland I, Pallesen S, Holsten F, Bjorvatn B: Seasonality is associated with anxiety and depression: the Hordaland health study. J Affect Disord 2008;105:147-155.

-37 Preacher KJ, Hayes AF: Asymptotic and resampling strategies for assessing and comparing indirect effects in multiple mediator models. Behav Res Methods 2008;40:879-891.

-38 Lehmann R, Denissen JJ, Allemand M, Penke L: Age and gender differences in motivational manifestations of the Big Five from age 16 to 60. Dev Psychol 2013;49:365-383.

-39 Jorm AF: Sex differences in neuroticism: a quantitative synthesis of published research. Aust N Z J Psychiatry 1987;21:501-506

40 Schag K, Schonleber J, Teufel M, Zipfel S, Giel KE: Food-related impulsivity in obesity and binge eating disorder - a systematic review. Obes Rev 2013;14:477-495. 